\title{
Effectiveness of educational program in maternal knowledge about neurodesarrollo in prematuros, hospital level III Chiclayo
}

\begin{abstract}
Introduction: In Peru there is a high incidence of premature newborns with various alterations. Nurses have the task of educating mothers about home care on neurodevelopmental and physiological functioning to prevent alterations of language, motor area and coordination of the child.

Objective: To evaluate the effectiveness of the educational program "pasitos de ternura" in the maternal knowledge about care of the premature child graduated in a hospital in Chiclayo, Peru.

Methods: A quasi-experimental quantitative study was carried out with the use of a validated survey before and after 5 sessions is educational every 15 days to 30 mothers of premature newborns. The chi-square test was used to evaluate the effectiveness of the educational program, with a confidence interval (CI) of $95 \%$, presenting a significant relationship if $\mathrm{p}<0.05$

Results: $33 \%$ of mothers presented a score of regular too bad before the educational program. There was an increase in the level of knowledge in 2.4 points, significantly after receiving the educational program $(95 \%$ CI 1.19-3.60, $\mathrm{t}=4.07, \mathrm{p}=0.000)$. The degree of maternal education had a significant correlation with the increase in the score $($ Spearman $=0.45, \mathrm{p}=0.012$ )

Conclusion: Maternal knowledge about premature newborn care is deficient, but after the implementation of the maternal education program a significant improvement of knowledge in the physiological and self-regulation aspects can be achieved, thus preventing repercussions in the child.
\end{abstract}

Keywords: effectiveness, educational program, knowledge, neurodevelopment, premature newborn
Volume 2 Issue 6 - 2018

\author{
Lilia Jannet Saldarriaga Sandoval,' Karina \\ Elizabeth Rodríguez Zúñiga,' Clarivel Diaz \\ Olano, ${ }^{2}$ Milton JM Rodríguez Zúñiga ${ }^{3}$ \\ 'Regional Hospital Specialist Lambayeque, National University of \\ Tumbes, Peru \\ ${ }^{2}$ Specialist National Hospital Almanzor Aguinaga Asenjo, \\ National University Pedro Ruiz Gallo, Peru \\ ${ }^{3}$ National University of San Marcos, Peru
}

Correspondence: Lilia Jannet Saldarriaga Sandoval, Regional Hospital Specialist Lambayeque, National University of Tumbes, Peru,Email livasa45@hotmail.com Received: September 04, 2018 | Published: November 16,
2018

\section{Introduction}

Prematurity has a worldwide incidence of around $11 \%$ of live births, with complications secondary to asphyxia such as cerebral palsy, learning problems and neurodevelopment. ${ }^{1}$ In Peru, $7.3 \%$ of all births are premature. On the other hand, in the hospital reference center of the northern macro region Teaching Regional Las Mercedes de Chiclayo, of the 3500 births per year, 1100 newborns (RN) are hospitalized in the neonatology service (SN), being $28 \%$ of them premature. ${ }^{2}$ In 2011, at the Level III-Chiclayo hospital, 144 premature RNs were reported, representing $22 \%$ of the RNs.

In addition to the economic problems associated with having a premature RN, 1 you parents are unaware of the care that should be offered to avoid complications short and long term. ${ }^{3}$ Such preventable complications are positional plagiocephaly, hip problems related to frog position, altered sleep and wake rhythm, difficulty in sucking and swallowing; lack of symmetry in the eyes and eye movements; difficulty in supporting the head, for the beginning of walking and vocalization. ${ }^{4}$

There are few publications on educational programs that help mothers avoid abnormalities in the development of their children. This educational task falls mainly on the nursing staff, who have the main mission of providing comprehensive care to the premature with their family, emphasizing their teaching role through the design and implementation of preventive activities Promotions aimed at the mother and benefit the premature newborn. ${ }^{5}$

Therefore the implementation of an educational program to identify problems that can affect the future life of the $\mathrm{RN}$ as well as recognize the mother as executor of health care of supervised premature oriented raised by the nurse, who must provide training and timely information, and thus improve individualized care by their caregivers. The aim of this study was to evaluate the effectiveness of "Pasitos of tenderness" educational program in maternal knowledge about neurodevelopmental graduate newborn neonatology service such Hospi Level III of Chiclayo premature.

\section{Material and methods}

A quasi-experimental study was conducted with 30 of the 144 mothers of premature babies hospitalized in the Neonatology service of the Regional Hospital who graduated from the neonatology service at the time of the study, during the months of March to August of 2015. We included mothers of preterm infants with gestational age between 28 and 36 weeks who were hospitalized and who, after discharge, had attended to the growth and development control in the pediatric office, and who had not presented complications in the puerperium, and who they agreed to participate voluntarily in the study. The mothers of 
premature babies born with APGAR 7 to 10 or who had congenital malformations were excluded.

The interview was used as a data collection technique before and after the educational program for the application of the maternal knowledge test on neurodevelopment of prematurity. Said test was elaborated by the authors (LS, KR and CD) based on the bibliographic review and it was constituted by a total of 16 items elaborated based on the conceptual framework; The mothers responded to the items by marking the $\mathrm{V}$ if they consider that the answer is true and $\mathrm{F}$ if they consider the answer to be false. Each correct answer was assigned the qualification of a point and was classified as good, regular and deficient knowledge if it achieved a score of 15 to 20,11 to 14 and 0 to 10 , respectively.

The educational program was elaborated by the authors based on the experience of nurses of the neonatology service and the bibliographic review, and consisted of 5 educational sessions entitled: "Our Premature", "The Positioning of the Premature", "Helping my baby to position correctly", "The importance of correctly positioning my premature baby ","Knowledge of stimulation of reflexes and language, "Knowledge of visual, olfactory and auditory stimulation", and "Identifying stress in our babies". At the end, the program was categorized as Effective if it increased the level of knowledge of the mothers of a deficient or regular level, at a good level, or Not Effective, when the level of knowledge of the mothers was maintained or decreased.

A pilot test of both the test and the educational program was carried out on 5 mothers of premature newborns from the same universe, who did not participate in the final sample. The instruments were validated by the trial of 02 nurse's specialists in Neonatology who offered suggestions for more clarity and specificity. With this, the maternal knowledge test on neurodevelopment of prematurity was tested for reliability with a Crombach's alpha of 0.687 and 0.567 , respectively.

The statistical data obtained were tabulated, processed and presented in tables and simple graphs. The main objective was to measure the effectiveness of the program. En statistical analysis Student 's t test was used to assess paired effectiveness with pre and post test with a confidence interval (CI) of $95 \%$, presenting a significant relationship if $<0.05$. Furthermore 1 was used to test's s t-student and Fisher's exact for the difference of means and difference of proportions, respectively. For the analysis or interpretation of the results the Stata statistical program was used 14.

The parents were informed to obtain their permission and consent to the present investigation. In addition, the principles of anonymity and confidentiality were respected, and the results obtained were notified to the institution. In addition, the present study involved the approval of the Hospital Ethics Committee.

\section{Results}

Of the 30 mothers included, $30 \%$ were between 16 and 20 years old, while $23.3 \%$ were between 21 and 25 years old. 24 of 30 mothers were married. $24 \%$ were illiterate or had incomplete primary education, while $40 \%$ had complete secondary or higher education. 5 mothers received medication during pregnancy, with antiemetics being the most frequent. In general, the mean hospital stay was 33.67 days (95\% CI 31.41-35.92).
The main objective was to evaluate the effectiveness of the program with the average of the pre and post test scores. The mean score was 14.9 pretest (95\% CI 13.70-16.09) and post test 17.3 (95\% CI 16.97 17.62). In total, there was an increase in the level of knowledge in 2.4 points, significantly ( $95 \%$ CI 1.19-3.60, $\mathrm{t}=4.07, \mathrm{p}=0.000)$.

By grouping by scores s and showed that prior to the program, $10 \%$ had a poor score, $23.3 \%$ regular and $66 \%$ good. After the program, $100 \%$ presented a good score. With this, the effectiveness reached $33.3 \%$ of the participants. Those in which it was effective, had an increase in 4 points (IC95\% 3.38-4.61), while those who remained in the same group, increased 1.65 points (IC95\% 1.21-2.09), the difference being significant $(\mathrm{z}=-6.06, \mathrm{p}=0.000)$.

When associating the effectiveness of the program with the socioepidemiological variables it was evidenced that only the degree of instruction had a significant correlation with the increase in the score after the program $($ Spearman $=0.45, \mathrm{p}=0.012)$.

\section{Discussion}

Our findings indicate that the Pasitos de Tendería Program was effective in increasing the level of knowledge in $33 \%$ of the mothers, reaching a level of good knowledge in $100 \%$ of them. In general, an increase of 2.4 points was registered, being higher in the group that climbed from a poor or regular level to a good level. Similar results have been reported by Cerdán ${ }^{6}$ in which the knowledge of the mothers before applying the educational program were: good in $33.33 \%$, regular in $46.67 \%$ and bad in $20 \%$. After the application of the educational program the results were: good in $46.67 \%$, regular in $50 \%$ and bad in $3.33 \%$. Thus, there was a significant increase in knowledge scores on premature newborn care at home.

The importance of our findings is to demonstrate that educational programs are effective in improving the knowledge of mothers, in addition to improving behaviors about the management and care of premature children. ${ }^{7,8}$

Our findings confirm that the educational level of the mother is a factor associated with obtaining a better result in the knowledge test. Other authors have shown that a higher educational level of the mother is significantly associated with a better cognitive and neurodevelopmental development of her child (OR 3.65, $\mathrm{p}=0.00) .{ }^{9}$ On the other hand, the education of parents predicts the degree of involvement of parents in the care of their children. Gallegos et al. ${ }^{10}$ showed that parents co $\mathrm{n}$ high education are involved in child care from admission, initiating its participation in child care in the neonatal unit, temple also do a positive predictor for the acquisition of skills for continuity of care at home.

The main objective of the education programs is to achieve the interest of the mothers and to share an adequate and necessary knowledge for the care of their children at home. On the other hand, in the Specialized Care units, educational programs must be planned in each of the groups of patients that the nursing professional cares for. ${ }^{11}$ Thus, the development of the educational program serves as a set of teaching strategies to facilitate the learning of mothers, incorporate new strategies of thoughts, methods and skills that allow improving the act of caring. ${ }^{12}$

The level of instruction has an approximation to the knowledge variable according to Bunge ${ }^{7}$ Knowledge is a set of ideas, concepts and communicable statements that can be ros, precise, orderly, vague 
or inaccurate class. It can be acquired in three different levels. The first is the sensitive one, in which an object is captured through the senses; such is the case of the images captured by sight. The conceptual consists of invisible representations, immaterial, but universal and essential. Finally, the intuitive by which an object is captured within a broad context, as an element of a whole, without clearly defined structures or limits. ${ }^{13}$

With the development of the program, the interest of mothers is achieved and their knowledge about health and disease increases. In the Specialized Care units, educational programs must be planned in each of the groups of patients that the nursing professional cares for. In the case of newborns, their parents are their self-care agent. Therefore, the mother of the hospitalized premature must have a knowledge base that allows her to respond to their care needs. Thus, strategies aimed at avoiding the consequences of prematurity are sought; in this way it is possible to improve the quality of life of the premature baby. ${ }^{14}$

Our results support the implementation of education programs for mothers of premature newborns in the areas of neonatology. We believe that the continuity of such education programs could improve the quality of life of premature babies, as well as reduce the anxiety of parents at home. ${ }^{3,8}$ Other authors have demonstrated the effectiveness of educational programs by having nurses as teachers and mothers as subjects of learning. ${ }^{15,16}$ The implementation of similar programs will ensure continuity of care in the home environment, favorably influencing the growth and development of premature newborns. ${ }^{6,12}$

One limitation of this study is that it cannot be assured which of the activities of the nursing educational intervention had greater weight in the change of the score of the self-care scale, so it could be an issue that would justify the realization of another investigation in aspects of the content of each educative session and to evaluate knowledge, in the mothers.

\section{Conclusion}

It was determined that the application of the educational program "Pasitos de ternura" for mothers of premature newborns was effective, achieving a highly significant increase in knowledge about neurodevelopment, physiological aspects and self-regulation of the stress of prematurity. The results of this research suggest that an educational nursing intervention such as the one presented in this article has a beneficial effect on the improvement of maternal knowledge and could achieve beneficial care behaviors in the premature newborn at home. In addition, the degree of instruction of the mothers would be a significant factor for a better use of the information provided in the educational sessions.

\section{Acknowledgements}

None.

\section{Conflict of interest}

The authors declare there is no conflict of interest.

\section{References}

1. Vesoulis ZA, Mathur AM. Cerebral autoregulation, brain injury, and the transitioning premature infant. Front Pediatr. 2017;5:64.

2. Levine LD, Gonzales GF, Tapia VL, et al. Preterm birth risk at high altitude in Peru. Am J Obstet Gynecol. 2015;212(2):210.e1-8.

3. Dutta S, Mahajan R, Agrawal SK, et al. Stress in fathers of premature newborns admitted in a neonatal intensive care unit. Indian Pediatr. 2016;53(4):311-313.

4. Gewolb IH, Vice FL. Abnormalities in the coordination of respiration and swallowing in preterm infants with bronchopulmonary dysplasia. Dev Med Child Neurol. 2006;48(7):595-599.

5. Raffray M, Semenic S, Osorio Galeano S, et al. Barriers and facilitators to prepare families with premature infants for discharge home from the neonatal unit. Perceptions of health care providers. Invest Educ Enferm. 2014;32(3):379-392.

6. Cerdan G. Effectiveness of the intervention of an educational program in the knowledge of mothers about the care of the premature newborn at home in San Bartolomé Hospital, in the period of August and September of 2004. Lima, Peru: UNMSM; 2004.

7. Bunge M. Science, its method and its philosophy. Buenos AiresArgentina: Editorial Sudamericana; 1997.

8. Araque S, Ariza N, Valderrama M. Educational strategy for home care of premature babies: mothers who use the kangaroo mother program in Tunja, Colombia. Rev Cuid. 2013;4(1):467-474.

9. Guzmán M, Guzmán F, Guzmán M, et al. Developmental disorders in children and adolescents in the region of Los Ríos, Valdivia, Chile, 2006-2008. Rev chil pediatr. 2015;86(5):345-350.

10. Gallegos M, Josefina O. Preterm hospitalized neonate: meaning of participation in a neonatal unity for the country. Latin-American Journal of Nursing. 2013;21(6):1360-1366.

11. Escalona A. Impact of a program on early stimulation in underweight children at the "José Martí" Polyclinic 2008 21st April. 2016.

12. Melgarejo G. Effectiveness of an educational program in the increase of mother's knowledge about her participation in the care of the premature in the neonatology service: Chancay Hospital - 2012. Lima, Peru: UNMSM; 2012.

13. Zilberstein T. Teaching learning and development. Chapter I. 2016.

14. Agami MS, Iglesias LJ, Bernárdez ZI, et al. Training of parents for the care of preterm children in their home. Rev Mex Pediatr. 2013;80(2):61-64.

15. De Miranda-Wosny A, Schülter I, Eggert A. Promoção da Saúde na Atenção Básica: basic study not Paulo Freire's method 2014; 19.

16. Alvarado A. The importance of positioning in the premature baby. Rev Mamis. 2014. 